\title{
Ceramics and its Importance
}

\author{
Mitra Mani Subedi \\ Department of Physics, Prithvi Narayan Campus, Pokhara, Nepal \\ subedimitramani@yahoo.com
}

\begin{abstract}
The term "ceramic" once referred only to clay-based materials. However, new generations of ceramic materials have tremendously expanded the scope and number of possible applications. Many of these new materials have a major impact on our daily lives and on our society. Ceramics has advanced far beyond its beginnings in clay pottery. Ceramic tiles cover the space shuttle as well as our kitchen floors. Ceramic electronic devices make possible high-tech instruments for everything from medicine to entertainment. Clearly, ceramics are our window to the future.
\end{abstract}

Keywords: electropositive, electronegative, bonding, crystalline, amorphous, photoconductivity

\section{INTRODUCTION}

Ceramic materials are inorganic, non-metallic materials made from compounds of a metal and a non metal. Ceramic materials may be crystalline or partly crystalline. They are formed by the action of heat and subsequent cooling. Clay was one of the earliest materials used to produce ceramics, as pottery, but many different ceramic materials are now used in domestic, industrial and building products. Ceramic materials tend to be strong, stiff, brittle, chemically inert, and non-conductors of heat and electricity, but their properties vary widely. For example, porcelain is widely used to make electrical insulators, but some ceramic compounds are superconductors.

A ceramic material may be defined as any inorganic crystalline material, compounded of a metal and a non-metal. It is solid and inert. Ceramic materials are brittle, hard, and strong in compression, weak in shearing and tension. They withstand chemical erosion that occurs in an acidic or caustic environment. In many cases withstanding erosion from the acid and bases applied to it. Ceramics generally can withstand very high temperatures such as temperatures that range from $1,000{ }^{\circ} \mathrm{C}$ to $1,600{ }^{\circ} \mathrm{C}$. Exceptions include inorganic materials that do not have oxygen such as silicon carbide. Glass by definition is not a ceramic because it is an amorphous solid (non-crystalline). However, glass involves several steps of the ceramic process and its mechanical properties behave similarly to ceramic materials.
Traditional ceramic raw materials include clay minerals such as kaolinite, more recent materials include aluminium oxide, more commonly known as alumina. The modern ceramic materials, which are classified as advanced ceramics, include silicon carbide and tungsten carbide. Both are valued for their abrasion resistance, and hence find use in applications such as the wear plates of crushing equipment in mining operations. Advanced ceramics are also used in the medicine, electrical and electronics industries.

\section{IMPORTANT PROPERTIES}

Ceramics can withstand high temperatures, are good thermal insulators, and do not expand greatly when heated. This makes them excellent thermal barriers, for applications that range from lining industrial furnaces to covering the space shuttle to protect it from high reentry temperatures.

Glasses are transparent, amorphous ceramics that are widely used in windows, lenses, and many other familiar applications. Light can induce an electrical response in some ceramics, called photoconductivity. Fiber optic cable is rapidly replacing copper for communications, as optical fibers can carry more information for longer distances withless interference and signal loss than traditional copper wires.

Ceramics are strong, hard, and durable. This makes them attractive structural materials. The one significant drawback is their brittleness, but this problem is being addressed by the development of new materials such as composites. 
Ceramics vary in electrical properties from excellent insulators to superconductors. Thus, they are used in a wide range of applications. Some are capacitors, others semiconductors in electronic devices. Piezoelectric materials can convert mechanical pressure into an electrical signal and are especially useful for sensors. There is now a strong research effort to discover new high $\mathrm{T}_{\mathrm{c}}$ superconductors and to develop possible applications.

The processing of crystalline ceramics follows the basic steps that have been used for ages to make clay products. The materials are selected, prepared, formed into a desired shape, and sintered at high temperatures. Glasses are processed by pouring in a molten state, working into shape while hot, and then cooling. New methods such as chemical vapor deposition and sol-gel processing are presently being developed.

The diversity in their properties stems from their bonding and structure.

\section{ATOMIC BONDING}

Two types of bonding mechanisms occur in ceramic materials, ionic and covalent. Often these mechanisms co-exist in the same ceramic material. Each type of bond leads to different characteristics.

Ionic bonds most often occur between metallic and nonmetallic elements that have large differences in their electronegativities. Ionically-bonded structures tend to have rather high melting points, since the bonds are strong and non-directional.

The other major bonding mechanism in ceramic structures is the covalent bond. Unlike ionic bonds where electrons are transferred, atoms bonded covalently share electrons. Usually the elements involved are nonmetallic and have small electronegativity differences.

Many ceramic materials contain both ionic and covalent bonding. The overall properties of these materials depend on the dominant bonding mechanism. Compounds that are either mostly ionic or mostly covalent have higher melting points than compounds in which neither kind of bonding predominates.

Table : Comparison of $\%$ covalent and ionic characters with the melting points.of several ceramic compounds

\begin{tabular}{|l|c|c|c|}
\hline \multicolumn{1}{|c|}{$\begin{array}{c}\text { Ceramic } \\
\text { compound }\end{array}$} & $\begin{array}{c}\text { Melting } \\
\text { point } \\
\left({ }^{\circ} \mathrm{C}\right)\end{array}$ & $\begin{array}{c}\% \\
\text { Covalent } \\
\text { character }\end{array}$ & $\begin{array}{c}\% \text { Ionic } \\
\text { character }\end{array}$ \\
\hline Magnesium oxide & 2798 & $27 \%$ & $73 \%$ \\
\hline Aluminum oxide & 2050 & $37 \%$ & $63 \%$ \\
\hline Silicon dioxide & 1715 & $49 \%$ & $51 \%$ \\
\hline Silicon nitride & 1900 & $70 \%$ & $30 \%$ \\
\hline Silicon carbide & 2500 & $89 \%$ & $11 \%$ \\
\hline
\end{tabular}

\section{CLASSIFICATION}

Ceramic materials can be divided into two classes: crystalline and amorphous (non-crystalline). In crystalline materials, a lattice point is occupied either by atoms or ions depending on the bonding mechanism. These atoms (or ions) are arranged in a regularly repeating pattern in three dimensions (i.e., they have long-range order). In contrast, in amorphous materials, the atoms exhibit only shortrange order. Some ceramic materials, like silicon dioxide $\left(\mathrm{SiO}_{2}\right)$, can exist in either form. A crystalline form of $\mathrm{SiO}_{2}$ results when this material is slowly cooled from a temperature $\left(\mathrm{T}>\mathrm{T}_{\mathrm{mp}} @ 1723^{\circ} \mathrm{C}\right)$. Rapid cooling favors non-crystalline formation since time is not allowed for ordered arrangements to form.

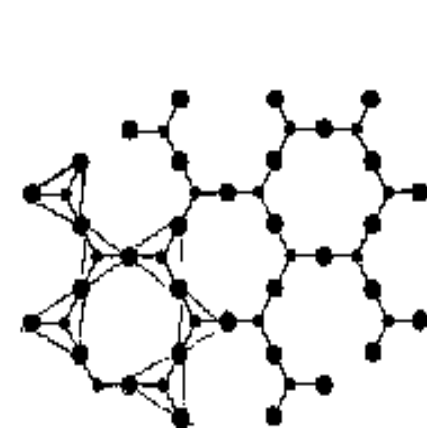

(i)

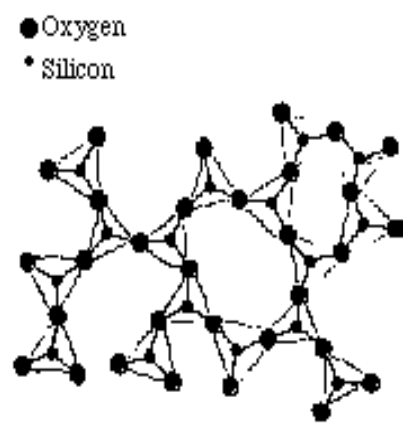

(ii)
Figure 1: Comparison of physical structures of (i) crystalline silicon dioxide (regular pattern) and (ii) amorphous silicon dioxide (random pattern) 
The type of bonding (ionic or covalent) and the internal structure (crystalline or amorphous) affects the properties of ceramic materials. The mechanical, electrical, thermal, and optical properties of ceramics will be discussed in the following sections.

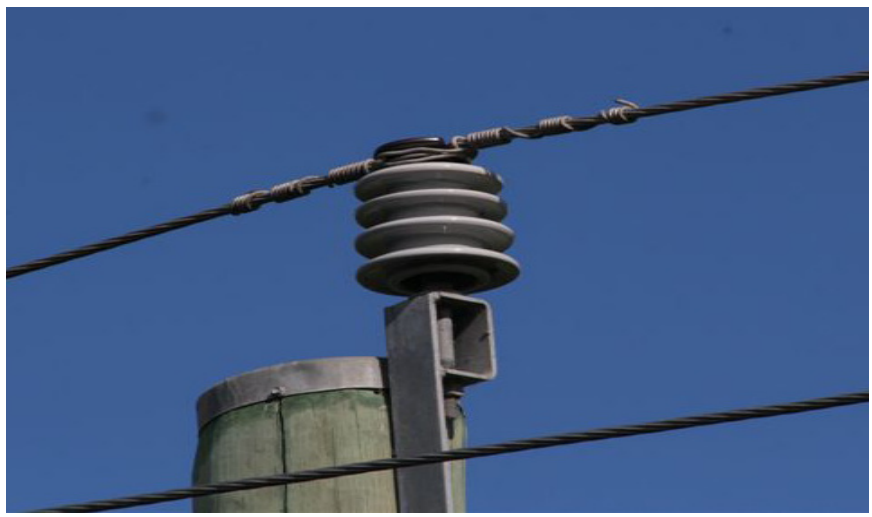

Figure 2: A typical ceramic insulator supporting a power line

\section{CONCLUSION}

Ceramic components can provide an excellent choice and new compositions are being continuously developed to give specific dielectric properties. New processes and advances in forming and manufacturing techniques introduced in recent years have led to the development of advanced ceramics with the properties and application potential to solve what were once regarded as seemingly impossible technical and engineering challenges.

\section{REFERENCES}

[1] C. Kittel, Introduction to Solid State Physics, Wiley Eastern Limited (5th Edition).
[2] Ceramics materials, 2013, The free encyclopedia.

[3] D.W. Richerson, Modern Ceramic Engineering, 2nd Ed., Marcel Dekker Inc., 1992, ISBN 0-8247-8634-3.

[4] Green, D.J.; Hannink, R.; Swain, M.V. (1989). Transformation Toughening of Ceramics. Boca Raton: CRC Press. ISBN 0-8493-6594-5.

[5] John B. Wachtman, Jr., ed., Ceramic Innovations in the 20th century, The American Ceramic Society, 1999, ISBN 978-1-57498-093-6.

[6] M.N. Rahaman, Ceramic Processing and Sintering, 2nd Ed., Marcel Dekker Inc., 2003, ISBN 0-8247-0988-8.

[7] M.W. Barsoum, Fundamentals of Ceramics, McGraw-Hill Co., Inc., 1997, ISBN 978-0-07005521-6.

[8] Subedi,M.M., An Experimental Study on Electrical Behavior of $\left(\mathrm{Pb}_{1-}{ }_{x} \mathrm{Sn} n_{x}\right)$ $\mathrm{TiO}_{3}(x=0.10,0.20,0.30)$ Ceramics, Dissertation Submitted to the CDP, T.U, Nepal.

[9] W.D. Kingery, H.K. Bowen and D.R. Uhlmann, Introduction to Ceramics, John Wiley \& Sons, Inc., 1976,ISBN 0-471-47860-1. 